\title{
SARCOPENIA, OBESITY AND SARCOPENIC OBESITY IN LIVER TRANSPLANTATION: A BODY COMPOSITION PROSPECTIVE STUDY
}

\author{
Sarcopenia, obesidade e obesidade sarcopênica em pacientes submetidos ao transplante hepático: Estudo prospectivo de composição corporal \\ Lucilene Rezende ANASTÁCIO ${ }^{1}$, Lívia Garcia FERREIRA ${ }^{2}$, Helem Sena RIBEIRO ${ }^{3}$, Kiara Gonçalves Dias DINIZ4 \\ Agnaldo Soares LIMA5, Maria Isabel T.D. CORREIA ${ }^{3}$, Eduardo Garcia VILELA ${ }^{5}$
}

\begin{abstract}
How to cite this article: Anastácio LR, Ferreira LG, Ribeiro HS, Diniz KGD, Limas AS, Correia MITD, Vilela EG. Sarcopenia, obesity and sarcopenic obesity in liver transplantation: a body composition prospective study. ABCD Arq Bras Cir Dig. 2019;32(2):e1434. DOI: /10.1590/0102$672020190001 \mathrm{e} 1434$
\end{abstract}

From the ${ }^{1}$ Programa de Pós-Graduação em Ciência dos Alimentos, Universidade Federal de Minas Gerais, Belo Horizonte, MG; ²Programa de Pós-Graduação em Nutrição e Saúde, Universidade Federal de Lavras, Lavras, MG; ${ }^{3}$ Instituto de Ensino e Pesquisa, Santa Casa de Belo Horizonte, Belo Horizonte, MG; ${ }^{4}$ Programa de Pós-Graduação em Saúde do Adulto, Faculdade de Medicina, Universidade Federal de Minas Gerais, Belo Horizonte, MG; ${ }^{5}$ Programa de PósGraduação em Cirurgia, Faculdade de Medicina, Universidade Federal de Minas Gerais, Belo Horizonte, MG ('Food Science Post-Graduation Program, Universidade Federal de Minas Gerais, Belo Horizonte, MG; ${ }^{2}$ Nutrition and Health PostGraduation Program, Universidade Federal de Lavras, Lavras, MG; ${ }^{3}$ nstituto de Ensino e Pesquisa, Santa Casa de Belo Horizonte, Belo Horizonte,MG; ${ }^{4}$ Adult Health Post-Graduation Program, Faculty of Medicine, Universidade Federal de Minas Gerais, Belo Horizonte, MG: ${ }^{5}$ Surgery Post-Graduation Program, Faculty of Medicine, Universidade Federal de Minas Gerais, Belo Horizonte, MG) Brazil

HEADINGS - Body mass index. Body composition. Liver transplantation. Sarcopenia.

\section{Correspondence:}

Lucilene Rezende Anastácio

E-mail: lucilene.rezende@gmail.com

Financial source: none

Conflict of interest none

Received for publication: 01/08/2018 Accepted for publication: 17/01/2019

DESCRITORES - índice de massa corporal. Composição corporal. Transplante hepático. Sarcopenia.
ABSTRACT - Background: Sarcopenia is prevalent before liver transplantation, and it is considered to be a risk factor for morbidity/mortality. After liver transplantation, some authors suggest that sarcopenia remains, and as patients gain weight as fat, they reach sarcopenic obesity status. Aim: Prospectively to assess changes in body composition, prevalence and associated factors with respect to sarcopenia, obesity and sarcopenic obesity after transplantation. Methods: Patients were evaluated at two different times for body composition, $4.0 \pm 3.2 \mathrm{y}$ and $7.6 \pm 3.1 \mathrm{y}$ after transplantation. Body composition data were obtained using bioelectrical impedance. The fat-free mass index and fat mass index were calculated, and the patients were classified into the following categories: sarcopenic; obesity; sarcopenic obesity. Results: A total of 100 patients were evaluated $(52.6 \pm 13.3 y$ ears; $57.0 \%$ male). The fat-free mass index decreased $\left(17.9 \pm 2.5\right.$ to $\left.17.5 \pm 3.5 \mathrm{~kg} / \mathrm{m}^{2}\right)$, fat mass index increased $(8.5 \pm 3.5$ to $9.0 \pm 4.0 ; \mathrm{p}<0.05)$, prevalence of sarcopenia (19.0 to $22.0 \%$ ), obesity ( 32.0 to $37.0 \%$ ) and sarcopenic obesity (0 to $2.0 \%$ ) also increased, although not significantly. The female gender was associated with sarcopenia. Conclusion: The fat increased over the years after surgery and the lean mass decreased, although not significantly. Sarcopenia and obesity were present after transplantation; however, sarcopenic obesity was not a reality observed in these patients.
RESUMO - Racional: A sarcopenia é prevalente antes do transplante de fígado e é considerada fator de risco para morbidade/mortalidade desses pacientes. Após o transplante hepático, alguns autores sugerem que a sarcopenia permanece, e os pacientes ganham peso na forma de gordura, atingindo o status de obesidade sarcopênica. Objetivo: Avaliar prospectivamente as mudanças na composição corporal, prevalência e fatores associados em relação à sarcopenia, obesidade e obesidade sarcopênica após o transplante. Métodos: Os pacientes foram avaliados em dois

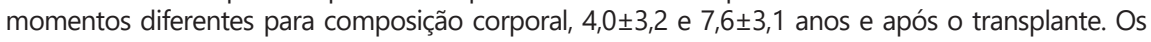
dados da composição corporal foram obtidos por meio de bioimpedância elétrica. $O$ índice de massa livre de gordura e o índice de massa gorda foram calculados, e os pacientes foram classificados nas seguintes categorias: sarcopênico; obesidade; obesidade sarcopênica. Resultados: Foram avaliados 100 pacientes (52,6 $6 \pm 13,3$ anos; $57,0 \%$ homens). A prevalência de sarcopenia (19,0\% para $22,0 \%$ ), obesidade $(32,0 \%$ para $37,0 \%)$ e índice de massa livre de gordura $\left(17,9 \pm 2,5\right.$ para $\left.17,5 \pm 3,5 \mathrm{~kg} / \mathrm{m}^{2}\right)$, índice de massa gorda aumentou $\left(8,5 \pm 3,5\right.$ para $\left.9,0 \pm 4,0 \mathrm{~kg} / \mathrm{m}^{2}\right)$, e obesidade sarcopênica (0 para $2,0 \%$ ) também aumentaram, embora não significativamente. O gênero feminino foi associado à sarcopenia. Conclusão: Após a operação, a gordura aumentou ao longo dos anos e a massa magra diminuiu, embora não significativamente. A sarcopenia e a obesidade estavam presentes após o transplante; no entanto, a obesidade sarcopênica não foi realidade observada nesses pacientes.

\section{INTRODUCTION}

S arcopenia is a syndrome that is characterized by progressive and generalized loss of skeletal muscle mass and strength associated with adverse outcomes such as physical disability, poor quality of life and death. There are several mechanisms that could be involved in the onset and progression of sarcopenia. They involve, among others, decreased protein synthesis, proteolysis, alterations in neuromuscular integrity and muscle fat content. In an individual with sarcopenia, several mechanisms could be involved, which could vary over time. Recognizing these mechanisms and their underlying causes is expected to facilitate the design of intervention trials that target one or more underlying causes of sarcopenia ${ }^{9,23}$. 
The diagnosis of low muscle mass could be accomplished using dual energy $X$-ray absorptiometry, computed tomography, bioelectrical impedance and sex-specific cutoffs ${ }^{9,31}$. Bioelectrical impedance is an easy, fast, low-cost and portable assessment device that can be used to diagnose sarcopenia among postliver transplant patients ${ }^{19,24}$.

Recently, some publications have addressed the sarcopenia diagnosis as well as its outcomes before and after liver transplantation ${ }^{8,28,29}$. Before the transplant, sarcopenia is highly prevalent, and it is seen in $41-68 \%$ of these patients ${ }^{13,20,21,27}$. After surgery, some authors depicted that the prevalence decreases - from $55 \%$ before liver transplantation to $30 \%$ after $^{3}$, and others have shown that in fact it increases from $62 \%$ before liver transplantation (LTx) to $87 \%$ after surgery ${ }^{28}$.

Despite the controversy on what occurs with sarcopenia after LTx, it is well known that patients gain too much weight and become obese after surgery. The median weight gain in the three years after the operation is $11.6 \pm 8.7 \mathrm{~kg}^{1}$, and the majority of the patients after LTx are overweight or obese ${ }^{2}$. Thus, one may wonder if the weight gain after LTx is a reflection of sarcopenic obesity and not necessarily an improvement in nutritional health ${ }^{5}$. Changes in the body composition of transplant recipients are characterized by an early and inappropriate gain in the fat mass, while the restoration of the body cell mass appears to occur more slowly, and it is incomplete ${ }^{10-26}$, which cannot be assessed by BMI (body mass index).

Therefore, the aim of this study was to verify prospectively the changes in the body composition as well as to depict the prevalence and associated factors of sarcopenia, obesity and sarcopenic obesity in LTx recipients and compare them with BMI status classifications.

\section{METHODS}

This is a prospective study that involves consecutive longterm liver transplant recipients. For body composition, these patients were evaluated at two different times throughout a four-year span. At the first evaluation, they were $4.0 \pm 3.2$ years after the liver transplant (median: 3 years; range $0-13$ years), and at the second, they were $7.6 \pm 3.0$ years after the operation (median: 7 years: range: $3-17$ years). The study was conducted at a single center (Transplant Outpatient Clinic), and was approved by the Ethics Committee (protocol number 44/08). All patients agreed to participate and signed the written consent.

The body composition data of the patients were obtained using bioelectrical impedance (RJL Systems ${ }^{\circledR}$ Quantum $\mathrm{X}$, Clinton Township, MI, USA). The previous preparation of the subjects, proposed by the study developer, consisted of the following protocol: subjects should not have exercised or taken a sauna within $8 \mathrm{~h}$ of the test and should refrain from alcohol intake for $12 \mathrm{~h}$ prior to the test, the height and weight of the subject should be accurately measured and recorded, and the subject should not be moist from sweat or lotion, have a fever, or be in shock. The subjects were also asked to remove metal objects, such as watches, glasses, jewelry, and other objects, which could interfere with the passage of electrical current, and to lie in a supine position with legs apart and arms away in parallel along the body. The electrodes for the bioimpedance measurement were placed on the right side of the body, and they were positioned in pairs on the back of the hand and foot.

The fat-free mass index (FFMI) and fat mass index (FMI) $\left(\mathrm{kg} / \mathrm{m}^{2}\right)$ were calculated, and the patients were classified in groups according to the following combinations: sarcopenia (low FFMI and normal FMI); obesity (normal FFMI and high FMI); sarcopenic obesity (low FFMI and high FMI); and normal body composition (normal FFMI and FMI). The FFMI was considered to be low when it was below $17.4 \mathrm{~kg} / \mathrm{m}^{2}$ in men and below $15.0 \mathrm{~kg} / \mathrm{m}^{2}$ in women ${ }^{12,17}$. The FMI was considered to be high when it was greater than $8.3 \mathrm{~kg} / \mathrm{m}^{2}$ in men and $11.8 \mathrm{~kg} / \mathrm{m}^{2}$ in women, according to Kyle et al. ${ }^{17}$ and Gonzalez et al. ${ }^{12}$. The patients were also classified using BMI classifications by the World Health Organization, namely, underweight $(\mathrm{BMl}<18.5 \mathrm{~kg} /$ $\mathrm{m}^{2}$ ), normal (BMI between 18.5-24.9 $\left.\mathrm{kg} / \mathrm{m}^{2}\right)$, overweight (BMI between $25.0-29.9 \mathrm{~kg} / \mathrm{m}^{2}$ ) and obese $\left(\mathrm{BMl}>30.0 \mathrm{~kg} / \mathrm{m}^{2}\right)^{30}$. The data collection included the gender, age, weight, height, and time since the operations, the first weight after LTx (to calculate the weight gain since the operation) and indication for LTx.

\section{Statistical analysis}

The data were evaluated by the Statistical Package for Social Sciences version 17.0 (SPSS Inc., Chicago, IL, USA). The numerical variables underwent the analysis of normality test (Kolmogorov-Smirnov) and presented as the mean and standard deviation because all of them had a normal distribution. Categorical variables were presented as absolute numbers and percentages. Comparisons of body composition data were performed using the paired t test and the Mc Nemar test. Associated factors for sarcopenia, obesity and sarcopenic obesity were assessed using the Chi-Square and Student T test. $p$ values lower than 0.05 were considered to be statistically significant.

\section{RESULTS}

A total of 100 patients transplanted were evaluated (52.6 \pm 13.3 years; $57.0 \%$ male). The most frequent indications for LTx were hepatitis C virus cirrhosis (29.0\%; $n=29)$, alcohol cirrhosis (26.0\%; $n=26)$, autoimmune hepatitis (13.0\%; $n=13)$, cryptogenic cirrhosis $(11.0 \% ; n=11)$; hepatocarcinoma $(6.0 \%$; $\mathrm{n}=6)$ and other indications (28.0\%; $\mathrm{n}=28)$.

It was observed that the amount of fat mass and the fat mass index significantly increased, while the percentage of fat-free mass decreased (Table $1, p<0.05$ ). The average weight gain was $1.6 \pm 7.2 \mathrm{~kg}$; however, the fat-free mass difference was $-0.8 \pm 8.0 \mathrm{~kg}$, and the fat mass difference was $1.7 \pm 6.9 \mathrm{~kg}$.

The prevalence of sarcopenia, obesity and sarcopenic obesity also increased over the years, but not significantly. Sarcopenia was prevalent in $22.0 \%(n=22)$ and obesity in $37.0 \%(n=37)$ of the patients over the long term after LTx. These disorders were widely prevalent on both assessed occasions, with only $49 \%$ of the patients having a normal body composition in the first assessment. However, sarcopenia and obesity do not co-exist in liver transplant recipients, as none in the first assessment and only two patients (in the later) were diagnosed with sarcopenic obesity (Table 1).

TABLE 1 - Fat-free mass, fat mass and body composition classification among long-term liver transplantation recipients over four years

\begin{tabular}{|c|c|c|c|}
\hline & First evaluation & $\begin{array}{l}\text { Second } \\
\text { evaluation }\end{array}$ & \\
\hline & $\begin{array}{c}\text { Average } \pm \text { standard } \\
\text { deviation } \\
\%(n)\end{array}$ & $\begin{array}{c}\text { Average } \pm \text { standard } \\
\text { deviation } \\
\%(n)\end{array}$ & $\mathrm{p}$ \\
\hline Weight & $72.2 \pm 16.6$ & $73.9 \pm 17.6$ & $0.027^{*}$ \\
\hline Body mass index $\left(\mathrm{kg} / \mathrm{m}^{2}\right)$ & $26.5 \pm 5.0$ & $26.3 \pm 5.6$ & 0.543 \\
\hline \multicolumn{4}{|l|}{$\begin{array}{l}\text { Variables related to fat- } \\
\text { free mass }\end{array}$} \\
\hline Fat-free mass (\%) & $68.4 \pm 8.8$ & $66.0 \pm 9.9$ & $0.027^{*}$ \\
\hline Fat-free mass $(\mathrm{kg})$ & $48.2 \pm 11.6$ & $48.2 \pm 11.6$ & 0.543 \\
\hline $\begin{array}{l}\text { Fat-free mass index } \\
\left(\mathrm{kg} / \mathrm{m}^{2}\right)\end{array}$ & $17.9 \pm 2.5$ & $17.5 \pm 3.5$ & 0.162 \\
\hline Total body water (L) & $36.3 \pm 8.1$ & $36.0 \pm 8.3$ & 0.432 \\
\hline \multicolumn{4}{|l|}{$\begin{array}{l}\text { Variables related to fat } \\
\text { mass }\end{array}$} \\
\hline Fat mass (\%) & $30.1 \pm 10.4$ & $32.1 \pm 10.4$ & 0.056 \\
\hline Fat mass (kg) & $22.4 \pm 9.5$ & $24.2 \pm 10.9$ & $0.006^{*}$ \\
\hline Fat mass index $\left(\mathrm{kg} / \mathrm{m}^{2}\right)$ & $8.5 \pm 3.5$ & $9.0 \pm 4.0$ & $0.038^{*}$ \\
\hline \multicolumn{4}{|l|}{$\begin{array}{l}\text { Body composition } \\
\text { classification }\end{array}$} \\
\hline Sarcopenia & $19.0 \%(19)$ & $22.0 \%(22)$ & 0.581 \\
\hline Obesity & $32.0 \%(32)$ & $37.0 \%(37)$ & 0.267 \\
\hline Sarcopenic obesity & $0.0 \%(0)$ & $2.0 \%(2)$ & - \\
\hline Normal & $49.0 \%(49)$ & $39.0 \%(39)$ & 0.263 \\
\hline
\end{tabular}


Considering the nutritional status by $\mathrm{BMI}$, four patients were underweight at the first assessment and two at the latter. Overweight was observed in 38 patients in the first evaluation and in 31 in the second, while the obesity rose from 22 to 27 patients. It was observed that sarcopenic patients were predominantly normal, overweight or obese according the BMI. Only one patient was underweight and sarcopenic in the first evaluation, and none in the second. Overweight and obesity by BMI were also considered in obese patients by body composition analysis; however, a substantial portion of them presented with normal BMI and were classified as obese by body composition assessment (Figure 1). Only two patients who were classified as sarcopenic obese were overweight and obese by BMI at the first assessment. Sarcopenic patients had similar BMIs to non-sarcopenic patients in both evaluations (Table 2), and in addition, with regard to the obese patients, the obese and non-obese patients by body composition did not differ with respect to BMI (Table 3).

Sarcopenia and obesity were not affected by age, time since transplantation, weight gain since transplant, and indication for liver transplant. Sarcopenic patients were predominantly women in both evaluations (12 of 19 patients in the first evaluation and 14 of 22 patients in the last evaluation) (Table 2). Obesity was similar among women and men (Table 3 ).

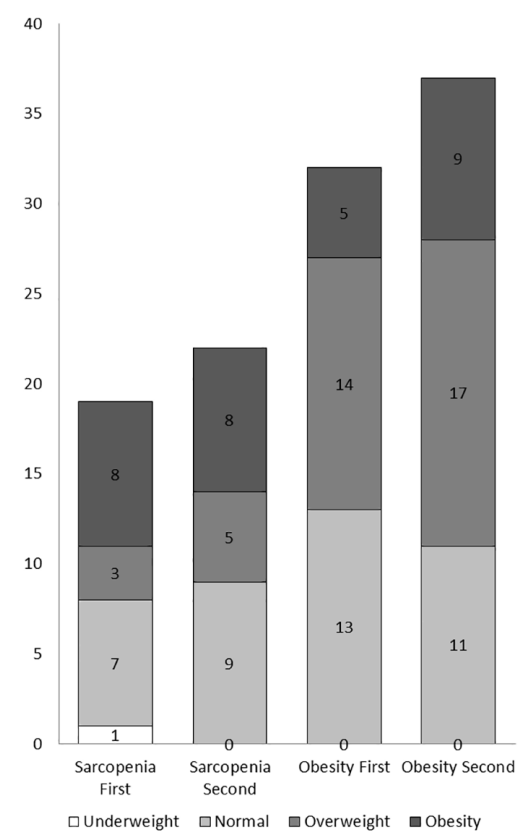

FIGURE 1 - Nutritional status classification using body mass index among liver recipients classified as sarcopenic and obese over four years

TABLE 2 - Variable distribution among sarcopenic liver transplantation recipients over four years

\begin{tabular}{|c|c|c|c|c|c|c|}
\hline \multirow{3}{*}{ Evaluation } & \multicolumn{3}{|c|}{ First evaluation } & \multicolumn{3}{|c|}{ Second evaluation } \\
\hline & Non-sarcopenic & Sarcopenic & & Non-sarcopenic & Sarcopenic & \\
\hline & $(n=81)$ & $(n=19)$ & $p$ & $(n=78)$ & $(n=22)$ & $p$ \\
\hline Age (years) & $45.2 \pm 13.2$ & $41.5 \pm 14.9$ & 0.286 & $53.1 \pm 13.2$ & $50.8 \pm 13.9$ & 0.489 \\
\hline Time since LTx (years) & $4.0 \pm 3.2$ & $4.1 \pm 3.2$ & 0.972 & $7.7 \pm 3.2$ & $7.1 \pm 2.4$ & 0.421 \\
\hline BMI $\left(\mathrm{kg} / \mathrm{m}^{2}\right)$ & $25.7 \pm 4.3$ & $28.7 \pm 8.9$ & 0.316 & $26.3 \pm 4.8$ & $27.6 \pm 5.7$ & 0.286 \\
\hline Weight gain since LTx & $10.0 \pm 8.8$ & $11.0 \pm 8.9$ & 0.671 & $12.1 \pm 11.3$ & $11.4 \pm 8.9$ & 0.788 \\
\hline \multicolumn{7}{|l|}{ Sex } \\
\hline Males & $87.7 \%(50)$ & $12.3 \%(7)$ & $0,049 *$ & $86.0 \%(49)$ & $14.0 \%(8)$ & $0.027^{*}$ \\
\hline Females & $72.1 \%(31)$ & $27.9 \%(12)$ & & $67.4 \%(29)$ & $32.6 \%(14)$ & \\
\hline \multicolumn{7}{|l|}{ Indication for transplant } \\
\hline Hepatitis C virus & $79.3 \%(23)$ & $20.7 \%(6)$ & 0.783 & $79.3 \%(23)$ & $20.7 \%(6)$ & 0.840 \\
\hline Ethanolic cirrhosis & $80.8 \%(21)$ & $19.2 \%(19)$ & 0.972 & $84.65(22)$ & $15.4 \%(4)$ & 0.344 \\
\hline Hepatitis auto-immune & $92.35(12)$ & $7.7 \%(1)$ & 0.265 & $84.6 \%(11)$ & $15.4 \%(2)$ & 0.537 \\
\hline Cryptogenic cirrhosis & $81.0 \%(81)$ & $19.05(19)$ & 0.942 & $81.8 \%(9)$ & $18.2 \%(2)$ & 0.746 \\
\hline Hepatocarcinoma & $100.05(6)$ & $0.0 \%(0)$ & 0.221 & $83.3 \%(5)$ & $16.75(1)$ & 0.605 \\
\hline Others & $78.6 \%(22)$ & $21.45(6)$ & 0.699 & $71.4 \%(20)$ & $28.6 \%(8)$ & 0.323 \\
\hline
\end{tabular}

$\mathrm{BMI}=$ body mass index; $\mathrm{LTX}=$ liver transplantation; Chi-square and T student test; ${ }^{*}=\mathrm{p}<0.05$

TABLE 3 - Variable distribution among obese liver transplantation recipients over four years

\begin{tabular}{|c|c|c|c|c|c|c|}
\hline \multirow{3}{*}{ Evaluation } & \multicolumn{3}{|c|}{ First evaluation } & \multicolumn{3}{|c|}{ Second evaluation } \\
\hline & Non-obese & Obese & $\mathrm{p}$ & Non-obese & Obese & \\
\hline & $(n=68)$ & $(n=31)$ & value & $(n=63)$ & $(n=37)$ & $p$ \\
\hline Age (years) & $45.0 \pm 13.3$ & $43.5 \pm 14.1$ & 0.607 & $52.6 \pm 13.2$ & $52.5 \pm 13.8$ & 0.974 \\
\hline Time since LTx (years) & $3.9 \pm 3.2$ & $4.3 \pm 3.2$ & 0.634 & $7.2 \pm 2.7$ & $8.2 \pm 3.4$ & 0.090 \\
\hline BMI $\left(\mathrm{kg} / \mathrm{m}^{2}\right)$ & $26.4 \pm 6.1$ & $26.0 \pm 4.3$ & 0.752 & $26.3 \pm 5.5$ & $26.9 \pm 4.1$ & 0.591 \\
\hline Weight gain since LTx & $10.4 \pm 9.2$ & $9.6 \pm 8.0$ & 0.656 & $12.1 \pm 10.7$ & $11.7 \pm 11.1$ & 0.871 \\
\hline \multicolumn{7}{|l|}{ Sex } \\
\hline Males & $63.2 \%(36)$ & $36.8 \%(21)$ & 0.232 & $56.1 \%(32)$ & $43.9 \%(25)$ & 0.102 \\
\hline Females & $74.4 \%(32)$ & $25.6 \%(11)$ & & $72.1 \%(31)$ & $27.9 \%(12)$ & \\
\hline \multicolumn{7}{|l|}{ Indication for transplant } \\
\hline Hepatitis C virus & $65.5 \%(19)$ & $34.5 \%(10)$ & 0.734 & $65.5 \%(19)$ & $34.5 \%(10)$ & 0.739 \\
\hline Ethanolic cirrhosis & $61.5 \%(16)$ & $38.5 \%(10)$ & 0.412 & $50.0 \%(13)$ & $50.0 \%(13)$ & 0.110 \\
\hline Hepatitis auto-immune & $69.2 \%(9)$ & $30.8 \%(4)$ & 0.919 & $53.8 \%(7)$ & $46.2 \%(6)$ & 0.464 \\
\hline Cryptogenic cirrhosis & $81.8 \%(9)$ & $18.2 \%(2)$ & 0.298 & $81.8 \%(9)$ & $18.2 \%(2)$ & 0.171 \\
\hline Hepatocarcinoma & $50.0 \%(3)$ & $50.0 \%(3)$ & 0.330 & $66.7 \%(4)$ & $33.3 \%(2)$ & 0.848 \\
\hline Others & $67.9 \%(19)$ & $32.1 \%(32)$ & 0.985 & $67.9 \%(19)$ & $32.1 \%(9)$ & 0.530 \\
\hline
\end{tabular}

$\mathrm{BMI}=$ body mass index; $\mathrm{LTx}=$ liver transplantation; Chi-square and T student test; ${ }^{*}=\mathrm{p}<0.05$. 
DISCUSSION

Sarcopenia is frequently associated with wasting syndromes and chronic diseases, such as cirrhosis. The presence as well as the consequences of this condition are well described in liver pre-transplant patients ${ }^{8,16,26,29}$. However, there are few data in the literature that report the prevalence, causes and impact of sarcopenia and sarcopenic obesity in patients after liver transplantation. Furthermore, when these data are reported, there are different methods and cutoff points to identify the prevalence, which hinders a comparison of the results obtained with this specific population.

In the present study, sarcopenia, obesity and sarcopenic obesity, as defined by body composition, increased over the four years, but not significantly. The prevalence of sarcopenia increased from $19 \%$ to $22 \%$ and obesity from $32 \%$ to $37 \%$. Sarcopenic obesity was not observed in patients at the first time point measured, but two of them acquired this condition four years later.

The prevalence of sarcopenia in long-term LTx patients is lower than that reported by other authors. Bergerson et al. ${ }^{3}$ conducted a study with 40 patients (alcoholic cirrhosis, non-alcoholic steatohepatitis cirrhosis, and primary sclerosing cholangitis cirrhosis) using images of computed tomography, and the reported the prevalence of sarcopenia in $55 \%$ preLTx patients, which decreased to $30 \%$ after transplantation (12-48 months after LTx). They considered skeletal muscle index cutoff levels for sarcopenia of $<38.5 \mathrm{~cm}^{2} / \mathrm{m}^{2}$ in women and $<52.4 \mathrm{~cm}^{2} / \mathrm{m}^{2}$ in men. A higher prevalence of sarcopenia was found by Tsien et al. ${ }^{28}$ by using images of computed tomography in addition to other measurements, and they reported that sarcopenia increased from $62.3 \%$ of their patients pre-transplant to $87 \%$ post-transplant, $19.3 \pm 9$ months after liver transplant. Additionally, in these patients, the fat area increased in 23 (43.4\%) and remained unchanged or decreased in the remaining 30 (56.6\%). In contrast to the previous reports on the development of obesity and the increase in fat mass after transplantation, the mean visceral and subcutaneous fat mass were unaltered in this cohort after transplantation ${ }^{28}$. Another study accessed 42 patients after liver transplantation, and of these, $48 \%$ had mid-arm fat area values that were above the $90^{\text {th }}$ percentile of the normal population, and they had a significantly lower body cell mass (BCM) (measured by the phase angle and compared with healthy controls), which reflects an abnormal body composition ${ }^{26}$. These authors concluded that the changes are characterized by an early and inappropriate gain in the fat mass, while the restoration of the BCM appears to occur more slowly and incompletely. The differences among the percentages of sarcopenia in the present study compared to other studies could be due to (in addition to the different methods and cutoffs) the longer time for the post-transplant assessment of the patients (an average of $4.0 \pm 3.2$ years after transplant in the first evaluation and $7.6 \pm 3.0$ years in the last evaluation). Some of the authors suggest that sarcopenia does not progress but is arrested and frequently improves after surgery ${ }^{3}$ and that sarcopenia progresses after LTx initially and does not recover at least within the first year after surgery ${ }^{6}$.

There are limited data about sarcopenic obesity in liver transplantation recipients, although weight gain and obesity are well established after transplantation ${ }^{1,7,26}$. Choudhary et al. ${ }^{7}$ evaluated 82 patients 24 months after LTx (varying from 12 to 38.5 months) by bioelectrical impedance. Although the cutoffs for sarcopenia were not described and obesity was defined by BMI>25 kg/m² plus visceral obesity, $88 \%$ of the patients were identified with sarcopenic obesity. In our study, BMI>25 kg/m ${ }^{2}$ was seen in $58 \%$ of the patients in the first evaluation, but sarcopenic obesity according to the definition of Kyle et al. ${ }^{17}$ and Gonzalez et al. ${ }^{12}$ was seen in only $2 \%$. The latter study evaluated the presence of sarcopenia in 175 cancer patients who were assessed before chemotherapy, and when both FMI and FFMI cutoffs were used, $58 \%$ of the patients were classified as obese, while only $1 \%$ were classified as presenting with a concurrent high FMI and low FFMI (sarcopenic obese) ${ }^{12}$.

In the present study, sarcopenic patients presented mostly as normal, overweight or obese by BMI. In addition, many patients with obesity by FMI were considered to be normal by the BMI classification. BMI does not accurately differentiate between lean from fat tissues, and thus, it does not provide information on whether excess FM, excess lean mass, or excess of both masses are present in patients who have excessive weight by the BMI criteria ${ }^{12}$. Furthermore, a normal or excessive weight for height does not necessarily mean lean mass because sarcopenic patients can be found among them. Additionally, patients with and without sarcopenia had similar BMIs, and the same held for obese patients who were identified by body composition. Obese patients also had similar weight gain since LTx than those without obesity.

Conversely, Jeon et al. ${ }^{25}$ showed a decrease in the $\mathrm{BMI}$ over the years $\left(24.6 \pm 3 \mathrm{~kg} / \mathrm{m}^{2}\right.$ pre-liver transplant to $23.3 \pm 3.1 \mathrm{~kg} / \mathrm{m}^{2}$ post-transplant, $\mathrm{p}=0.015$ ) in sarcopenic patients compared to those without sarcopenia. Most of these patients $(79 \%, n=52, p<0.001)$ already had sarcopenia before liver transplantation, and an increase was observed in the incidence of sarcopenia after liver transplantation. Another study that enrolled patients on the waiting list for liver transplantation showed that their BMI was associated with an increased prevalence of sarcopenia [100\% (8/8) with a $\mathrm{BMI}<18.5 \mathrm{~kg} / \mathrm{m}^{2}$ (underweight), 46\% (29/63) with a BMI 18.6-25 kg/m² (normal weight), and 30\% (21/71) with a $\mathrm{BMI}>25 \mathrm{~kg} / \mathrm{m}^{2}$ (overweight), $\left.\mathrm{p}<0.001\right]$. The mean $\mathrm{BMI}$ of the sarcopenic patients was within the normal weight range, which is the same result that was found in our study $(24.2$ $\mathrm{kg} / \mathrm{m}^{2}$ - IQR $\left.1 / 420.4-26.2 \mathrm{~kg} / \mathrm{m}^{2}\right)^{27}$.

The only associated factor that was identified as a risk factor for sarcopenia was gender, because age, prior obesity, and indication for transplant did not have an impact. Surprisingly, the prevalence of sarcopenia was significantly higher in women $(27.9 \%$ in the first assessment and $32.6 \%$ in the last) than in men (12.3\% and $14 \%)$, which differs from studies that showed the opposite ${ }^{4,21}$. In aging men, the percentage of fat mass increases initially, and then it levels off or decreases. Such a change has been attributed to an accelerated decrease in the lean mass, along with an initial increase and a later decrease in the fat mass. Women show a generally similar pattern. The intramuscular and visceral fat increased with age while the subcutaneous fat declined ${ }^{9}$.

The lack of unanimous criteria to define low muscle mass and high fat mass to identify cases of sarcopenic obesity represents a major clinical and research drawback ${ }^{24}$. Different methods and cutoffs make it difficult to compare data. Additionally, a consensus on sarcopenia ${ }^{9,23}$ recommends that the diagnosis could be made in the presence of both low muscle mass and low muscle function (strength or performance), but most studies that were conducted on LTx patients used only low muscle mass. The criteria are somewhat arbitrary and study-specific, which could have minimized the predictive value of sarcopenic obesity as a health risk factor ${ }^{25}$. The lack of standardized diagnostic approaches is reflected in the variable combination of body composition indices and cutoffs that have been used to classify sarcopenic obesity. The latter could be a limitation of the risk prediction when considering either sarcopenia or obesity alone ${ }^{24}$. In a study with a general middle-age population $(n=654)$, the prevalence of sarcopenia ranged from $0 \%$ to $45.2 \%$, depending on the used methods and 
cutoffs, and only one participant was identified as having sarcopenia according to all of the diagnostic criteria ${ }^{4}$. The gold standard assessments the body composition involve body-imaging techniques, such as computed tomography and magnetic resonance followed by dual energy $\mathrm{X}$-ray absorptiometry (DXA), as the preferred alternative method.

There are some limitations with regard to the use of bioelectrical impedance, as differences in the measurement protocols can be found, resulting in proportional or positional bias. In addition, the use of statistically derived, populationspecific equations (typically height, weight, age, gender, and ethnicity specific) that have mostly been validated among healthy and normal-weight individuals under highly controlled conditions ${ }^{22}$ and cross-validation in independent samples is generally lacking, except among healthy adults ${ }^{18}$. In addition, assessments of change in the FFM with singlefrequency bioimpedance, especially after weight loss or gain either intentionally or owing to illness, could differ from reference measurements ${ }^{18}$. Nevertheless, in clinical practice, the European Working Group on Sarcopenia in Older People ${ }^{9}$ indicates bioelectrical impedance analysis (BIA) as a good portable alternative method. BIA has also been suggested for the systematic and repeated evaluation of FFM in clinical practice because it is safe, portable and inexpensive, and in addition, it is quick and simple to use ${ }^{14}$. BIA measurement techniques, when used under standard conditions, have been studied for $>10$ years and may be a good alternative to DXA. The measurements are sensitive to subject conditions such as hydration and recent activity, and the instrument predictions could be population specific. However, a study was performed with 215 teenagers to assess the predictive ability of four different BIA devices with and without a performance protocol. When compared to DXA, it was concluded that in most cases, the BIA data were similar to DXA in the same evaluation without protocol, which indicates the reliability of data when it is not possible to perform the protocol ${ }^{11}$. Indicators of fat free mass and fat mass have been adjusted to account for the differences in body sizes. The adjustment for height squared has been the preferred method, but the adjustment for body weight has also been utilized ${ }^{24}$. Some limitations of the study should be highlighted, as the lack of an initial evaluation prior to transplantation or immediately after surgery to know the baseline situation of the patients and be able to study their subsequent evolution.

\section{CONCLUSION}

Fat mass increased over the years after surgery, and lean mass decreased, although not significantly. Sarcopenia and obesity were highly present after LTx, with increasing prevalence over the years, which resulted in less than half of the patients having a normal body composition at both evaluations. However, sarcopenic obesity was not a reality that was observed in these long-term patients. The $\mathrm{BMI}$, weight gain, age and indication for LTx did not affect sarcopenia and obesity. Females had a greater prevalence of sarcopenia. Sarcopenic patients were the majority among normal, overweight or obese patients by BMI, and some obese patients by BIA were classified as normal weight by BMI criteria.

\section{AKNOWLEDGMENT}

We thank Pró-Reitoria de Pesquisa da Universidade Federal de Minas Gerais for language support review and FAPEMIG (Fundação de Amparo à Pesquisa do Estado de Minas Gerais),
CNPq (Conselho Nacional de Pesquisa) and CAPES (Coordenação de Aperfeiçoamento de Pessoal de Nível Superior) for grants.

\section{REFERENCES}

1. Anastacio L, Garcia Ferreira L, Costa Liboredo J, de Sena Ribeiro $H$, Soares Lima A, Garcia Vilela E, et al. Overweight, obesity and weight gain up to three years after liver transplantation. Nutr Hosp. 2012;27(4):1351- 6.

2. Anastacio LR, Pereira MCA, Vilela EG, Lima AS, Correia MITD. Excesso de peso em pacientes submetidos ao transplante hepático. Rev Col Bras Cir. 2013:40(6):502-07.

3. Bergerson JT, Lee JG, Furlan A, Sourianarayanane A, Fetzer DT, Tevar AD, et al. Liver transplantation arrests and reverses muscle wasting. Clin Transplant. 2015;"29(3):216-21.

4. Bijlsma AY, Meskers CG, Ling CH, Narici M, Kurrle SE, Cameron ID, Westendorp RGJ, et al. Defining sarcopenia: the impact of different diagnostic criteria on the prevalence of sarcopenia in a large middle aged cohort. Age (Dordr). 2013;35(3):871-81.

5. Carey EJ. Sarcopenia in solid organ transplantation. Nutr Clin Pract. 2014;29(2):159-70.

6. Carias S, Castellanos AL, Vilchez V, Nair R, Dela Cruz AC, Watkins J, Barret T, et al. Nonalcoholic steatohepatitis is strongly associated with sarcopenic obesity in patients with cirrhosis undergoing liver transplant evaluation.J Gastroenterol Hepatol. 2016;31(3):628-33.

7. Choudhary NS, Saigal S, Saraf N, Mohanka R, Rastogi A, Goja S, Menon $P$, et al. Sarcopenic obesity with metabolic syndrome: a newly recognized entity following living donor liver transplantation. Clin Transplant. 2015;29(3):211-5.

8. Clark K, Cross T. Sarcopenia and survival after liver transplantation. Liver Transpl. 2014;20(11):1423.

9. Cruz-Jentoft AJ, Baeyens JP, Bauer JM, Boirie Y, Cederholm T, Landi F, et al. Sarcopenia: European consensus on definition and diagnosis: Report of the European Working Group on Sarcopenia in Older People. Age Ageing. 2010;39(4):412-23

10. Ferreira LG, Santos LF, Anastacio LR, LimaAS, Correia MI. Resting energy expenditure, body composition, and dietary intake: a longitudinal study before and after liver transplantation. Transplantation. 2013:96(6):579-85.

11. Goncalves VS, Faria ER, Franceschini Sdo C, Priore SE. Predictive capacity of different bioelectrical impedance analysis devices, with and without protocol, in the evaluation of adolescents. J Pediatr (Rio J). 2013; 89(6):567- 74.

12. Gonzalez MC, Pastore CA, Orlandi SP, Heymsfield SB. Obesity paradox in cancer: new insights provided by body composition. Am J Clin Nutr. 2014;99(5):999-1005.

13. Hanai T, Shiraki M, Nishimura K, Ohnishi S, Imai K Suetsugu A, et al. Sarcopenia impairs prognosis of patients with liver cirrhosis. Nutrition. 2015;31(1):193-9.

14. Heymsfield SB, Gonzalez MC, Lu J, Jia G, Zheng J. Skeletal muscle mass and quality: evolution of modern measurement concepts in the context of sarcopenia. Proc Nutr Soc. 2015;74(4):355-66.

15. Jeon JY, Wang HJ, Ock SY, Xu W, Lee JD, Lee JH, Kim HJ, et al. Newly Developed Sarcopenia as a Prognostic Factor for Survival in Patients who Underwent Liver Transplantation. PLoS One. 2015;10(11):e0143966

16. Kalafateli M, Mantzoukis K, Choi Yau Y, Mohammad AO, Arora $\mathrm{S}$, Rodrigues $\mathrm{S}$, Vos $\mathrm{M}$, et al. Malnutrition and sarcopenia predict post-liver transplantation outcomes independently of the Model for End-stage Liver Disease score. J Cachexia Sarcopenia Muscle. 2017:8(1):113-121

17. Kyle UG, Pirlich M, Lochs H, Schuetz T, Pichard C. Increased length of hospital stay in underweight and overweight patients at hospital admission: a controlled population study. Clin Nutr. 2005;24(1):133-42

18. Lukaski HC. Evolution of bioimpedance: a circuitous journey from estimation of physiological function to assessment of body composition and a return to clinical research. Eur J Clin Nutr. 2013; 67 Suppl 1:S2-9.

19. Marini E, Buffa R, Saragat B, Coin A, Toffanello ED, Berton L, et al. The potential of classic and specific bioelectrical impedance vector analysis for the assessment of sarcopenia and sarcopenic obesity. Clin Interv Aging. 2012;7:585-91.

20. Masuda T, Shirabe K, Ikegami T, Harimoto N, Yoshizumi T, Soejima $Y$, et al. Sarcopenia is a prognostic factor in living donor liver transplantation. Liver Transpl. 2014;20(4):401-7.

21. Montano-Loza AJ. Severe muscle depletion predicts postoperative length of stay but is not associated with survival after liver transplantation. Liver Transpl. 2014;20(11):1424.

22. Mulasi U, Kuchnia AJ, Cole AJ, Earthman CP. Bioimpedance at the bedside: current applications, limitations, and opportunities. Nutr Clin Pract. 2015;30(2):180-93. 
23. Muscaritoli M, Anker SD, Argiles J, Aversa Z, Bauer JM, Biolo G, et al. Consensus definition of sarcopenia, cachexia and pre-cachexia: joint document elaborated by Special Interest Groups (SIG) "cachexia-anorexia in chronic wasting diseases" and "nutrition in geriatrics". Clin Nutr. 2010;29(2):154-9.

24. Prado CM, Heymsfield SB. Lean tissue imaging: a new era for nutritional assessment and intervention. JPEN J Parenter Enteral Nutr. 2014;38(8):940-53

25. Rolland Y, Czerwinski S, Abellan Van Kan G, Morley JE, Cesari M, Onder G, Woo J, et al. Sarcopenia: its assessment, etiology, pathogenesis, consequences and future perspectives. J Nutr Health Aging. 2008;12(7):433- 50.

26. Schutz T, Hudjetz H, Roske AE, Katzorke C, Kreymann G, Budde K, Fritshe, $L$, et al. Weight gain in long-term survivors of kidney or liver transplantation-- another paradigm of sarcopenic obesity? Nutrition. 2012;28(4):378-83.

27. Tandon P, Ney M, Irwin I, Ma MM, Gramlich L, Bain VG, et al. Severe muscle depletion in patients on the liver transplant wait list: its prevalence and independent prognostic value. Liver Transpl. 2012;18(10):1209-16.
28. Tsien C, Garber A, Narayanan A, Shah SN, Barnes D, Eghtesad B, et al. Post-liver transplantation sarcopenia in cirrhosis: a prospective evaluation. J Gastroenterol Hepatol. 2014;29(6):1250-7.

29. Valero V, 3rd, Amini N, Spolverato G, Weiss MJ, Hirose K, Dagher $\mathrm{NN}$, et al. Sarcopenia adversely impacts postoperative complications following resection or transplantation in patients with primary liver tumors. J Gastrointest Surg. 2015;19(2):272-81.

30. World Health Organization W. Obesity: preventing and managing the global epidemic. 894 N, editor. Geneva:World Health Organization; 2000.

31. Yoshizumi T, Shirabe K, Nakagawara H, Ikegami T, Harimoto N Toshima T, et al. Skeletal muscle area correlates with body surface area in healthy adults. Hepatol Res. 2014;44(3):313-8. 